\title{
RETRACTED ARTICLE: Temporal and non-temporal contextual saliency analysis for generalized wide-area (GWA) search within UAV video
}

\author{
Mostafa Al-Gabalawy ${ }^{1}$
}

Accepted: 12 November 2020 / Published online: 3 January 2021

○) Springer-Verlag GmbH Germany, part of Springer Nature 2021

The Editor-in-Chief has retracted this article because it was previously published by different authors [1]. The content has been removed for legal reasons. The author disagrees with this retraction.

\section{Reference}

1. https://github.com/Hoclor/CoSADUV-Contextual-Saliency-forDetecting-Anomalies-in-UAV-Video/blob/a7242e30b8f4cbac9028 7a8077eedaa8725d5470/Temporal_Contextual_Saliency_for_ Wide_Area_Search_in_UAV_Video.pdf

\begin{abstract}
Mostafa Al-Gabalawy was born in 1983, Egypt. He obtained a B.Sc. in Electrical Engineering from Cairo University, 2005, with an honors degree. In 2011, he obtained an M.Sc. in Electrical Engineering from Cairo University. In 2017, he obtained a PhD in Electrical Engineering from Ain Shams University. Currently, I'm the leader for the courses of automatic control and artificial intelligence in Pyramids Higher Institute for Engineering and Technology since 2018 till now.
\end{abstract}

Mostafa Al-Gabalawy

mostafagabalawy@gmail.com

1 Electrical Power Engineering and Automatic Control

Department, Pyramids Higher Institute for Engineering and Technology, 6th of October City, Egypt 